\title{
A Renewable Energy Fed Non-Isolated Inverse Output Voltage DC-DC Converter with Broad Range of Conversion
}

\author{
M. Praveen Kumar, P. Maheeth, M. Sai Krishna Reddy, S. Ravi Teja
}

\begin{abstract}
Renewable Energy fed non-isolated negative output Converter with dc-dc conversion is proposed which employed for various applications. In industrial purposes only few converters are available for wide conversion ratio, the proposed design has come up with wide range negative voltage load applications. The proposed converter is analyzed and design for continuous condition mode. For verification of theoretical analysis, the proposed converter is simulated using PSIM 9.0.
\end{abstract}

Index Terms: Negative output, Wide Gain, Buck-Boost, Non-isolated.

\section{INTRODUCTION}

DC-DC converters plays significant role in manufacturing requirements since their usage is inevitable. Applications mainly like inverting charge pump, audio amplifiers, digital camera, in hybrid electric vehicles for regeneration purpose of dc motors (RBS), buck-boost voltage inverter, for generation of wind power and power generation from photo voltaic. [1]-[4], etc.

As familiar as there are two typical traditional converters, they are traditional buck-boost converter and CUK converter gives a reverse output. Where $\mathrm{D}$ is the duty cycle and their conversion ratio of voltage is $(-D /(1-D)$ is same. They can produce the output voltage has higher or lower compared to the input voltage. Hypothetically, these converters will produce the output voltage as weather high step-up or step-down. Duty cycle is approximately equal to 0 or 1 , still real-world operation. This condition will not be met for the diodes and the power switches [5]-[6]. A transformer will be used for fly-back converter to get wide conversion ratio of an output voltage. The switch voltage of the transformer will be exceeding, and EMI difficulties occurs, and which causes for low efficiency and vast volume [7]. Vast number of Inverse output converters have been suggested in this past decade, suppose, the voltage conversion ratio $\mathrm{M}(\mathrm{d})=-\mathrm{D}$ for the topology of the inverse output KY buck-boost converter who had the fast load transient response was suggested in [8]. $\mathrm{M}(\mathrm{d})=-2 \mathrm{D}$ is the voltage conversion ratio for the N/O

Revised Version Manuscript Received on Jun 20, 2019.

M.Praveen kumar, B.Tech, Dept. of Electrical and Electronic Engineering, KLEF, Vaddeswaram, Guntur,INDIA Engineering, KLEF, Vaddeswaram, Guntur,INDIA

M.Sai Krishna Reddy, Asst.Professor,Dept. of Electrical and Electronic Engineering, KLEF, Vaddeswaram, Guntur,INDIA

S.Ravi Teja, Asst. Professor,Dept. of Electrical and Electronic Engineering, KLEF, Vaddeswaram, Guntur,INDIA
Pochanapeddi Maheeth, B.Tech, Dept. of Electrical and Electronic

KY-Buck-Boost converter who possessed no additive characteristics was suggested in [9].

The topology of the inverse output KY-buck-boost has been built the path for the Boost converter is integrated as positive to inverse with voltage conversion ratio as $-1 /(1-D)$ was suggested in [10].

In this paper is planned as following manner. The regulation and stable state analysis of the prompt device area unit outlined in section II. PSIM simulations to verify theoretical analysis are presented in section III. Conclusions are made available at the end of the paper.

\section{STEADY STATE ANALYSIS}

We can see from Figure 1.1, the suggested converter forms of input voltage $v_{i n}$, from PV panel and two active devices and two passive devices $D_{1}$ and $D_{2}$, it consists of two inductors $L_{1}$ and $L_{2}$, two capacitors $C$ and $C_{0}$ and only single load resistance R. For steady state operation details and analysis of the converter it is assumed to that all the components are ideal, also the inductors and capacitors are large enough to maintain ripple almost negligible and to operate converter in

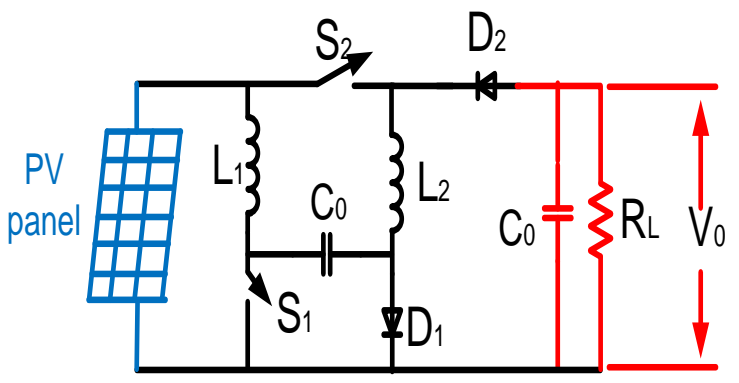

Figure-1.1 Proposed converter circuit diagram

\section{Interval-1 ( $T_{o n^{-}}$condition)}

During this interval active switches are on and passive devices are in OFF condition. This case equivalent circuit is shown in figure 2. we have derived the voltage across the inductors and current through the capacitors as follows.

$$
\begin{aligned}
& \mathrm{L}_{1} \frac{d i_{L 1}}{d t}=v_{i n} \\
& \mathrm{~L}_{2} \frac{d i_{L n}}{d t}=v_{i n}+v_{C} \\
& \mathrm{C} \frac{d v_{C}}{d t}=-i_{L 2} \\
& C_{0} \frac{d v_{0}}{d t}=-\frac{v_{0}}{R}
\end{aligned}
$$

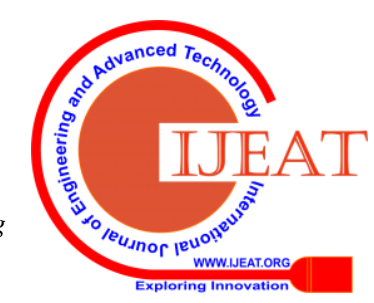




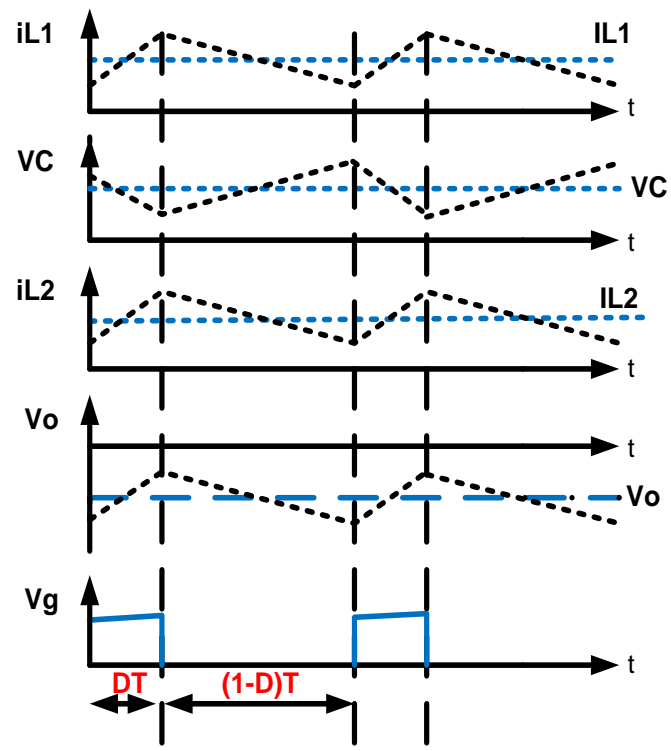

Figure 1.2 shows steady state waveforms of the proposed converter

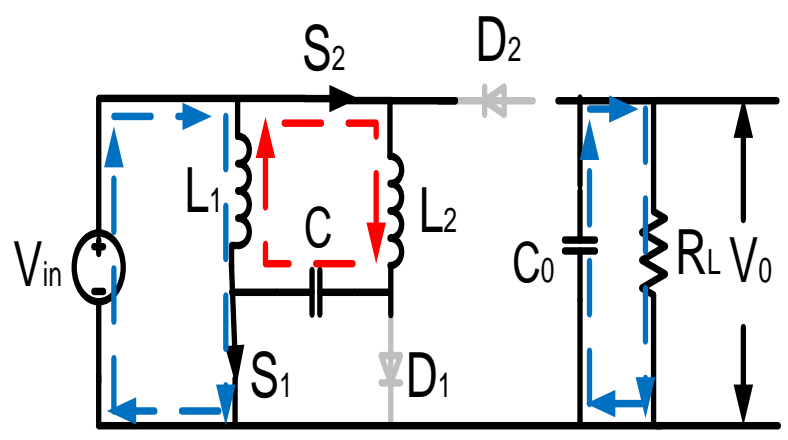

Figure-2 ON state equivalent circuit

\section{Interval-II ( $\boldsymbol{T}_{\text {off- }}$ condition)}

During this interval active devices are in off condition and passive devices are forward biased. This case equivalent circuit is shown in figure-3. The voltage across inductors and current through capacitors are derived as follows.

$$
\begin{aligned}
& \mathrm{L}_{1} \frac{d i_{L 1}}{d t}=v_{i n}-v_{c} \\
& \mathrm{~L}_{2} \frac{d i_{L n}}{d t}=v_{0} \\
& \mathrm{C} \frac{d v_{C}}{d t}=i_{L 1} \\
& C_{0} \frac{d v_{0}}{d t}=-i_{L 2^{-}} \frac{v_{0}}{R}
\end{aligned}
$$

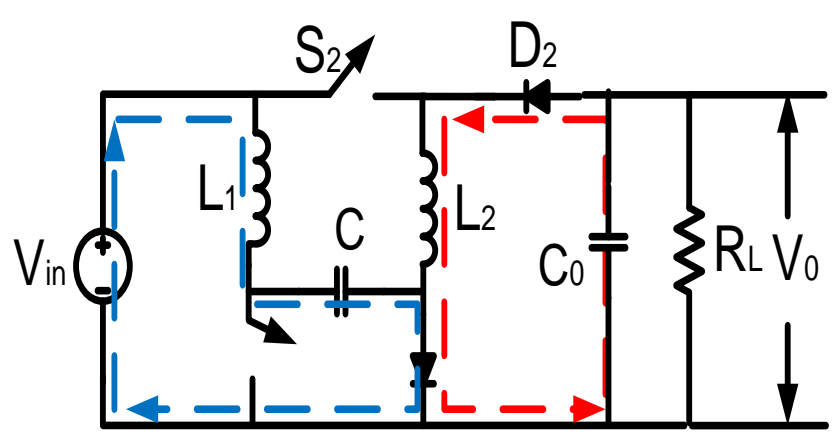

Figure-3 OFF state equivalent circuit
Applying volt-sec balance for both the inductors and solved for relation between input voltage and output voltage as follows.

$$
\begin{aligned}
& \mathrm{D}_{v_{i n}}+\left((1-D)\left(V_{i n}-V_{c}\right)=0\right. \\
& \mathrm{D}\left(v_{i n}+v_{c}\right)+(1-\mathrm{D}) v_{o}=0
\end{aligned}
$$

Consequently, we have resulting $V_{c}$ and $V_{0}$ from (1) and (2)

$$
\begin{aligned}
& v_{\mathrm{C}}=\frac{1}{(1-\mathrm{D})} \mathrm{v}_{\text {in }} \\
& \mathrm{v}_{\mathrm{o}}=-\frac{\mathrm{D}(2-\mathrm{D})}{(1-\mathrm{D})^{2}} v_{\text {in }}
\end{aligned}
$$

Therefore, we have represented the gain of the suggested converter as

$$
\mathrm{M}=\frac{v_{0}}{v_{\text {in }}}=-\frac{D(2-D)}{(1-D)^{2}}
$$

Apparently, if the duty cycle D is lesser than 0.29 , the voltage gain $\mathrm{M}$ is a smaller amount than one, the prompt device works in step down voltage mode in such the simplest way, else it works in boost mode. Whereas the conventional buck-boost converter operates at $\mathrm{D}<0.5$ for buck mode and D> 0.5 for boost mode which restricts gain. The below equations represents the blocking voltages of switches and diodes

$$
\begin{aligned}
& v_{D 1}=\frac{v_{i n}}{(1-D)} \\
& v_{D 2}=\frac{v_{i n}}{(1-D)^{2}} \\
& v_{S 1}=\frac{v_{i n}}{(1-D)} \\
& v_{S 2}=\frac{v_{i n}}{(1-D)^{2}}
\end{aligned}
$$

\section{SIMULATED RESULTS}

To validate the theoretical analysis and design the proposed converter is simulated in PSIM 9.0.4. The following simulation parameters are taken into consideration which is shown in table-I. The output voltage from PV panel set to $20 \mathrm{~V}$ and the converter operated in two mode buck mode and boost

mode for meeting voltage requirements of signal generator and data transmission applications.

\section{Table-I}

Parameters of main circuit

\begin{tabular}{|l|l|l|}
\hline Specification & Buck Mode & Boost mode \\
\hline $\begin{array}{l}\text { PV panel Output } \\
\text { voltage }\end{array}$ & $20 \mathrm{~V}$ & $20 \mathrm{~V}$ \\
\hline $\begin{array}{l}\text { Converter Output } \\
\text { voltage }\end{array}$ & $-13.47 \mathrm{~V}$ & $-105 \mathrm{~V}$ \\
\hline Operating frequency & $40 \mathrm{kHz}$ & $40 \mathrm{kHz}$ \\
\hline Load resistor & $10 \Omega$ & $10 \Omega$ \\
\hline Duty ratio & 0.23 & 0.6 \\
\hline Inductor L1 & $0.8 \mathrm{mH}$ & $0.8 \mathrm{mH}$ \\
\hline Inductor L2 & $1 \mathrm{mH}$ & $1 \mathrm{mH}$ \\
\hline Capacitor C1 & $10 \mu F$ & $10 \mu F$ \\
\hline Capacitor C2 & $44 \mu F$ & $44 \mu F$ \\
\hline
\end{tabular}

Here the inductor currents in buck mode has shown in Fig-4 and the inductor current ripple during in buck mode is very low. In fig-5 shows the output voltage and intermediate capacitor voltage 
during buck mode it can be seen that the voltage ripple of the capacitor is very low. In Fig-6 blocking voltages of the active switches during buck mode which shows low value. In fig-7 inductor currents during boost mode shown having lowest ripple. In fig- 8 shows the output voltage and intermediate capacitor voltage during boost mode it can be seen that the voltage ripple of the capacitor is very low. Fig-9 shows blocking voltages of the active switches during boost mode which shows low value.
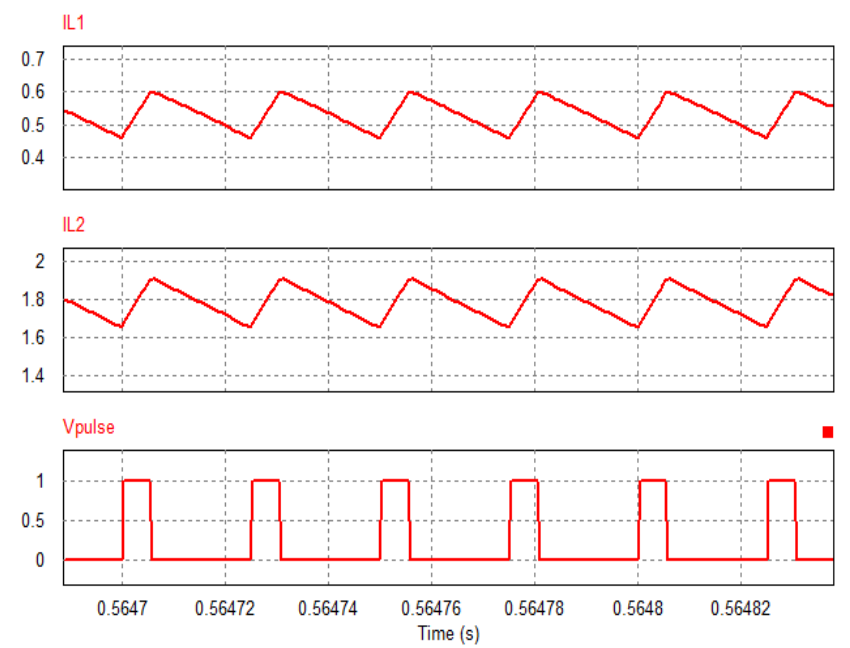

Figure-4 Inductor currents in buck mode

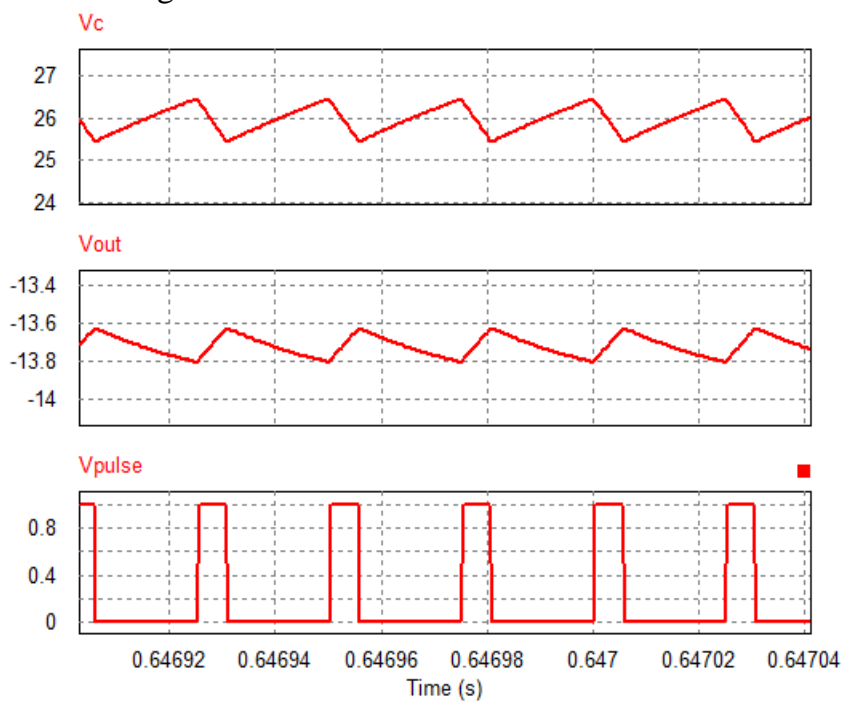

Figure-5 Output voltage and intermediate capacitor voltage during buck mode

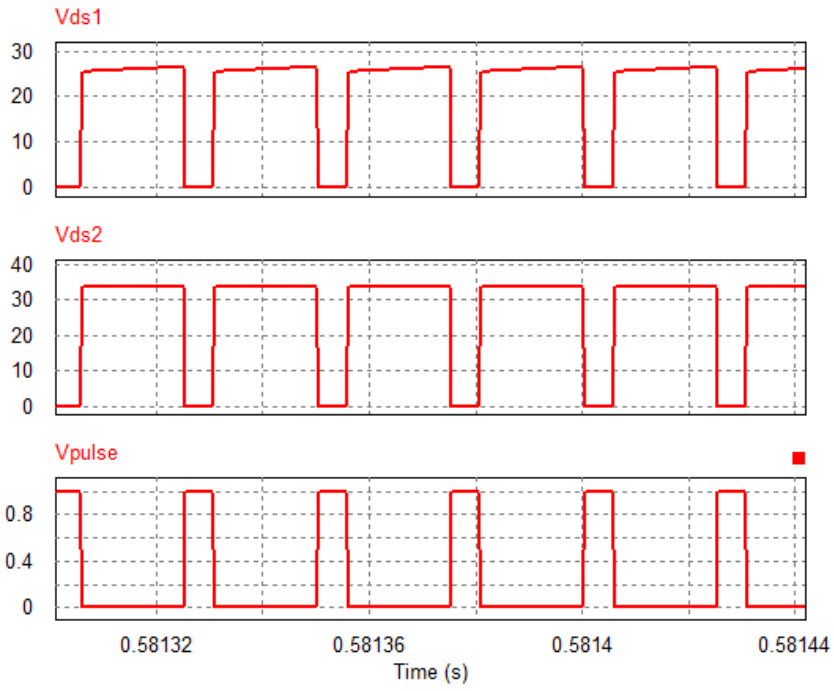

Figure-6: Switch blocking voltage during buck mode

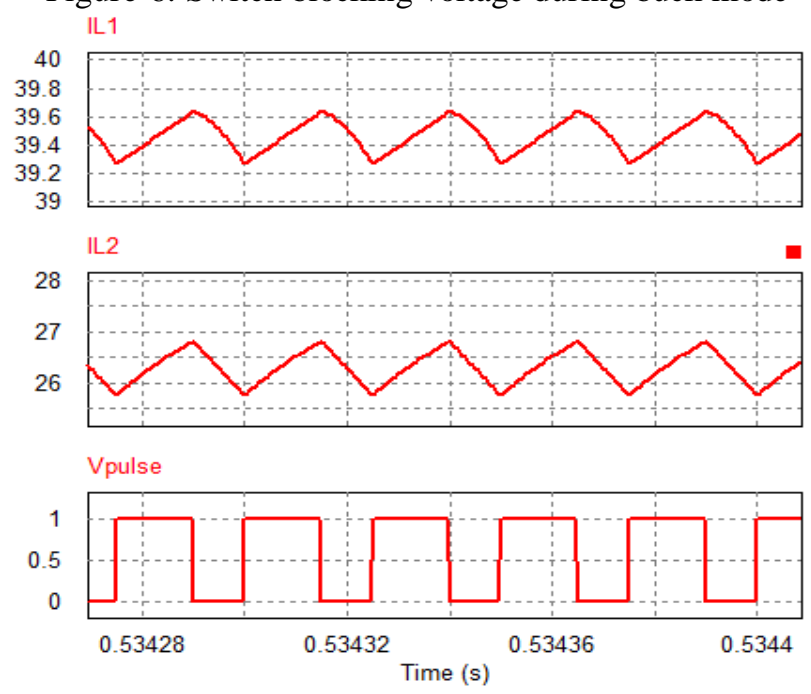

Figure-7 Inductor currents in boost mode
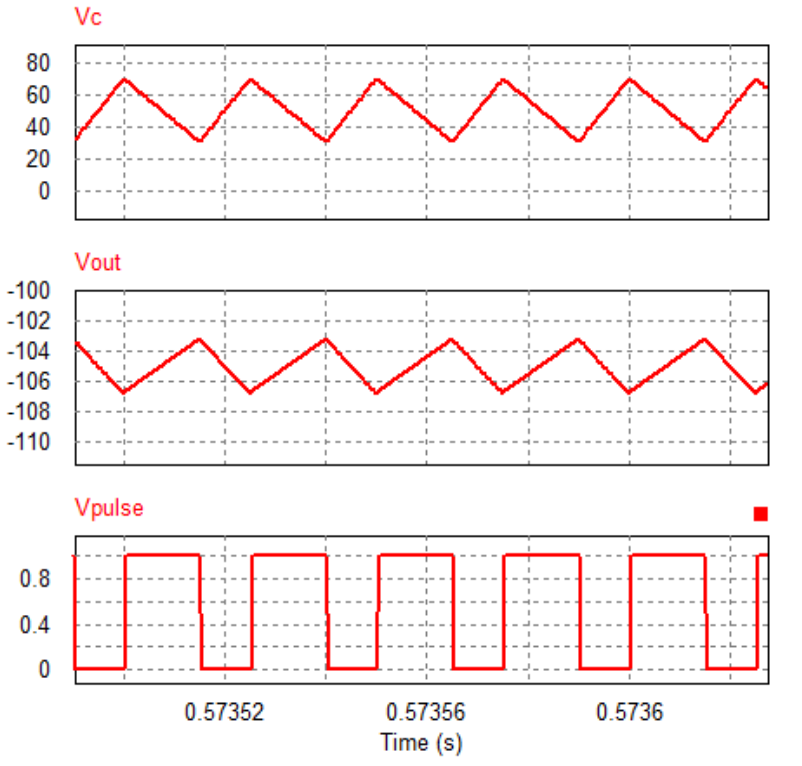

Figure-8 Output voltage and intermediate capacitor voltage during boost mode

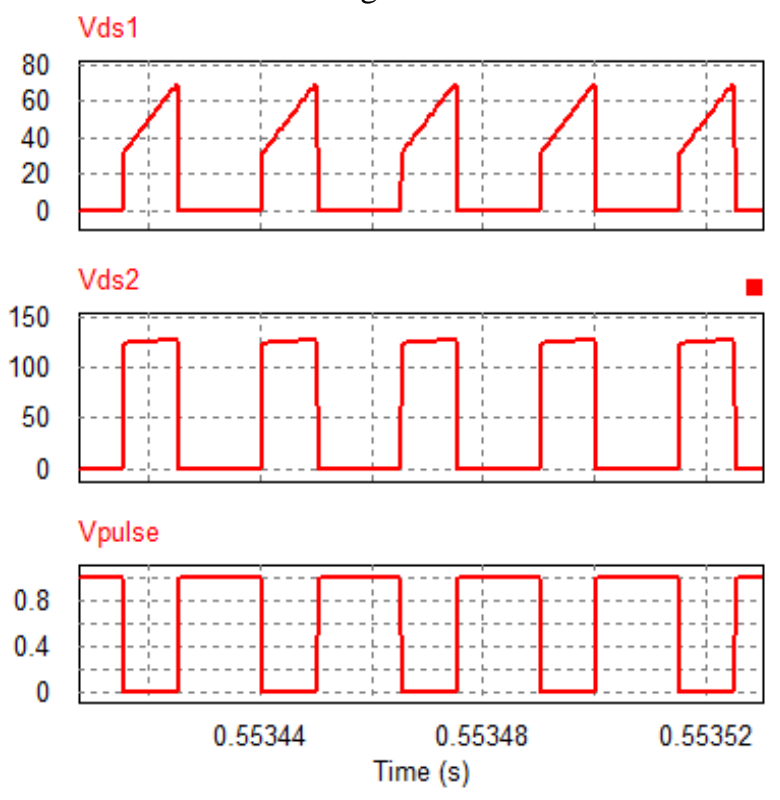

Figure-9: Switch blocking voltage during boost mode

Published By:

Blue Eyes Intelligence Engineering \& Sciences Publication 


\section{CONCLUSION}

A Non-Isolated inverse output for Buck-Boost device is recommended, evaluated and authorized during this project paper. The steady state analysis has been done and the simulations are verified to validate the analysis. It is observed that the proposed converter have highest gain which allows the converter suitable for broad conversion ranges. Also, from results low ripple content can be observed for inductor currents and capacitor voltages which makes component selection easy.

\section{REFERENCES}

1. F.L. Luo, "Inverse Output Luo Converter; For Voltage Lift Technique," Iee Pioc. Electr.Power Appl., Vol.146, No: -2, Pp.208-224, Mar-1999.

2. M. Zhu And F.L. Luo, "Enhanced Self-Lift Cuk Converter For Inverse Output Voltage Conversion," Ieee Trans. On Power Electron., Vol.25, No:9, Pp,2227-2233, Sep,2010.

3. K.I. Hwu, Y.T. Yau And J.J. Shieh, "Inverse Output Resonant Voltage Divi Der"In Proc.Ieee Power Electronics And Driver Systems

4. A. Cocor, A. BAESEU, AND A. Florescu," Elementary AND SELF-LIFT INVERSE OUTPUT LUO DC-DC CONVERTERS USED IN Hybrid CARS," U.P.B. SCI.Bull., SERIES C, VOl,77, Iss,4, PP, 179-190,2015.

5. B.AXELROD,Y,BERKOVICH,ANDA,IOINOVICI"SWITCHED-CAPACITOR/S WITCHED-INDUCTOR STRUCTURES FOR GETTING TRANSFORMER LESS DC-DC PWM CONVERTERS," IEEE TRANS, CIRCUITS SyST I, FunDAM. THEORY APPL., VOL.55, N0.2, PP.687-696, MAR.2008

6. O. Abutbul, A Gherlitz, Y. Berkovich, AND A. IONiOvici," STEP-UP SWITCHING-MODE CONVERTER WITH High VOLTAGE GAIN USing A Switched CAPACITOR Circuit," IEeE Trans. Circuits SYSt. I, Fundamental TheORY APPl., VOL. No.8, PP.1098-1102, AUG.2003.

7. Y. TANG, T. WANG, AND Y. He, "SOFT SWITCHING INVERSE OUTPUT Ky Buck Boost Converter," In Proc. IEeE Trans. Power ELECTRON.VOL.29, No.6, PP.1053-1060.

8. K. I HWU AND Y. T YaU, "A Swithed CAPACITOR Based ACTIVE NETWORK CONVERTER With High VOlTAge GaIN," IEE TrANS.POWER ElECTRON., VOL.29 N0.6, PP.2959-2968, JUN.2014

9. K. I HWU, Y.T YAU AND Z.F. LIN, "INVERSE OUTPUT BUCK BOOST CONVERTER," IN PROC. IEEE INDUSTRIAL ELECTRONICS AND APPLICATIONS CONF., MAY 2009, PP.3347-3350

10. K. I HwU, W.C TU AND Y.H. CHEN, “A NOVEL INVERSE OUTPUT KY Buck-Boost CONVERTER”, In Proc. IEEe POWER EleCtronics AND DRIVE SYS2009, PP....V.2009, PP.1155-1157

11. M. SAI KRISHNA REDDY AND ElANGOVAN. "ANALYSIS AND Simulation OF ZCS CURRENT FED Full BRIDGE CONVERTER WiTH SYNCHRONOUS RECTIFICATION” IEEE PCCCTSG-2015, 183-185

12. SENTHIL KUMAR K, M. SAI KRISHNA REDDY, D ElANGOVAN AND DR. R. SARAVAN KUMAR “ INTERLEAVE ISOLATED BOOST CONVERTER AS FRONT END CONVERTER FOR FUEL CELL APPLICATION” IEEE, ICEES-2014, 202-205

\section{AUTHORS PROFILE}

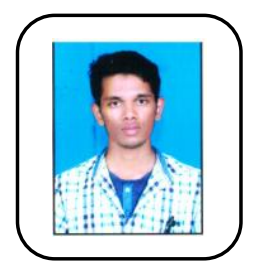

M.Praveen Kumar was born in Andhra Pradesh,India.He is pursuing his Bachelor's degree in electrical and electronics engineering from KLEF, Vaddeswaram, Guntur His research interests include electrical drives, power electronics, electric machines, renewable-energy systems, and electrical hybrid vehicles.

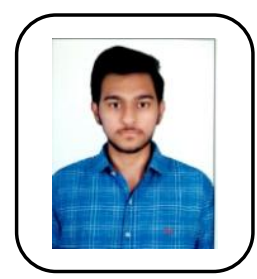

Pochanapeddi Maheeth was born in Andhra Pradesh,India.He is pursuing his Bachelor's degree in electrical and electronics engineering from KLEF, Vaddeswaram, Guntur His research interests include electrical drives, power electronics, electric machines, renewable-energy systems, and electrical hybrid vehicles. 